\title{
Categorização nominal em línguas Arawák: revisando a questão de gênero gramatical
}

DOI: http://dx.doi.org/10.21165/el.v49i3.2658

\section{Camille Cardoso Miranda ${ }^{1}$}

\section{Resumo}

Corbett $(1991,2001)$ e Aikhenvald (2000a) assumem que gênero e classe nominal são um tipo de categorização nominal. Diferentemente desses autores, Grinevald (2000) estabelece uma distinção de gênero e classe nominal, alegando que gênero é um termo geralmente reservado para sistemas relativamente pequenos, baseados no sexo, do tipo indo-europeu, enquanto classes nominais são geralmente usadas para além da questão do sexo, como animado/inanimado, humano/não humano, macho/fêmea etc. Assim sendo, para esta pesquisa utilizaremos a abordagem teórica de Corbett (1991), classificando gênero e classe de nomes em uma mesma categoria: gênero. O presente trabalho tem como objetivo realizar um estudo comparativo-tipológico para verificar a questão de gênero em dez línguas da família Arawák. Como resultado, verificamos que essas línguas atribuem gênero por questões semânticas com mais predominância do que formal e que em algumas línguas, como Paresi, Mehináku, Terena e Wauja, por exemplo, a distinção de gênero se perdeu.

Palavras-chave: tipologia morfológica; categorização nominal; línguas Arawák.

1 Universidade Estadual de Campinas (UNICAMP), Campinas, São Paulo, Brasil; camiranda126@gmail.com; https://orcid.org/0000-0002-3920-6247 


\title{
Nominal categorization in the languages Arawak: reviewing the grammatical genre issue
}

\begin{abstract}
Corbett $(1991,2001)$ and Aikhenvald (2000a) assume that gender and nominal class are a type of nominal categorization. Unlike these authors, Grinevald (2000) distinguishes between gender and nominal class, claiming that gender is a term generally reserved for relatively small, gender-based Indo-European systems, whereas nominals class are generally used for the issue of sex, as animate/inanimate, human/nonhuman, male/ female etc. Therefore, for this research we will use the theoretical approach of Corbett (1991), classifying gender and nominal class in the same category: gender. The present work aims to carry out a comparative-typological study to verify the issue of gender in ten languages of the Arawák family. As a result, we verify that these languages attribute gender for semantic issues more predominantly than formal and that in some languages such as Paresi, Mehináku, Terena and Wauja, for example, have lost their gender distinction.
\end{abstract}

Keywords: morphological typology; nominal categorization; Arawak languages.

\section{Introdução}

Deacordo com Kilarski (2013), as descrições de classificação nominal são frequentemente caracterizadas por uma proliferação de ambiguidades e termos intercambiáveis que apresentam um obstáculo na análise de classificação dos sistemas individuais e em propriedades comuns estabelecidas pela classificação nominal. Para Lucy (2000, p. 329), a classificação de nomes compartilha uma função referencial na medida que contribuem para uma referência nominal adequada do nome. Desse modo, uma base referencial comum manifesta-se no núcleo semântico nos sistemas de gênero e classe nominal, uma vez que os critérios semânticos também desempenham um papel importante nos sistemas que são atribuídos numa base morfológica e semântica, com isso, não há sistema de classe nominal ou gênero em que todo o sistema de classificação seja puramente formal.

Diante disso, o presente trabalho tem como objetivo realizar um estudo comparativotipológico para verificar a questão de gênero gramatical em 10 línguas da família Arawák. Desse modo foram selecionadas cinco línguas do grupo Norte-Arawák (Achaguá, Baniwa de Içana, Baré, Palikur, Warekena) e cinco línguas do grupo Sul-Arawák (Baure, Mehináku, Paresí, Terena, Wauja). Um dos resultados apresentados é que em geral essas línguas exibem dois sistemas de gênero (masculino vs. feminino) que estão presentes no sintagma nominal ou no verbo (uma relação de trans-referência). Verificamos também que algumas línguas não apresentam afıxos de gêneros presos gramaticalmente, mas fazem uma referência a esse sistema por meio do léxico (ex. Terena, Wauja); há também línguas 
como Paresi, Mehináku e Terena que o sistema de gênero é raro ou está se perdendo. Contudo, verificamos que essas línguas atribuem gênero por questões semânticas com mais predominância do que formal, uma vez que quase todas elas, embora tenha marcação morfológica, apresentam também uma distinção semântica para distinguir o sexo do referente.

Esse trabalho, além da introdução, é dividido em quatro seções. A primeira seção traz algumas informações sobre a família Arawák. A segunda seção exibe algumas considerações da questão de gênero/classe nominal. Na terceira seção exemplificamos a questão de gênero nas línguas Arawák aqui selecionadas. Por último, na quarta seção, com base nos aportes teóricos discutidos, realizaremos uma análise preliminar dos perfis tipológicos encontrados em relação à categoria de gênero nessas línguas.

\section{A família Arawák}

A família Arawák (Aruák) contém um número amplo de línguas faladas na América do Sul. Aikhenvald (1999) afirma que, geograficamente, as línguas dessa família se expandem para quatro países da América Central - Belize, Honduras, Guiana, Nicarágua e em oito países da América do Sul - Bolívia, Guiana Francesa, Suriname, Venezuela, Colômbia, Peru, Brasil, Argentina e Paraguai. Atualmente, são aproximadamente 30 ou 40 línguas Arawák que permanecem vivas, mas esse número pode variar.

Aikhenvald (1999) afirma que a unidade genética das línguas Arawák foi reconhecida pela primeira vez por Father Gilij em 1978. O reconhecimento da família foi baseado sobre uma comparação de Maipure, do Vale do Orinoco e Moxo da Bolívia. Gilij denominou a família Arawák como Maipure, mas Brinton e Von der Steinen a denominou como seu nome atual, Arawák (Aruák). Esse nome vem a partir de uma língua conhecida como Lokono Arawák ou Lokono Dian, ainda falada na Guiana Francesa, Suriname e Venezuela (AIKHENVALD, 2012).

Os estudos comparativos iniciados por Gilij foram continuados por Von den Steinen que propôs a primeira subdivisão das línguas Arawák. Ele distingue Nu-Arawák de Ta-Arawák, baseando-se na forma do prefixo pronominal de primeira pessoa. Outros estudos dessa família foram realizados por Brinton (1891) e Payne (1991). Aikhenvald (1999) explica que embora não exista dúvida da afiliação genética das línguas Arawák, problemas ainda podem ser encontrados no que diz respeito à relação genética entre a família e possíveis relações genéticas com outros grupos. Com relação às propriedades gramaticais das línguas da família Arawák, Aikhenvald (1999) explica que elas são facilmente reconhecidas por compartilharem alguns aspectos gramaticais em comum, tais como, o prefixo nominal de primeira pessoa singular $\{n \mathrm{n}-\}$ ou $\{$-ta\}, o morfema $\{\mathrm{pi}-\}$ que se refere à segunda pessoa do singular, o prefixo \{ka-\} que codifica oração relativa ou atributiva como "ter" e etc. No que diz respeito aos estudos de tipologia morfológica, a autora explica que as línguas desta família apresentam propriedades de línguas aglutinantes e polissintéticas. 
As línguas analisadas para este trabalho são agrupadas geograficamente em diferentes grupos por Aikhenvald (1999). O quadro 1 abaixo (adaptado) exibe o agrupamento das línguas selecionadas para esse trabalho, de acordo com Aikhenvald (1999).

Quadro 1. Agrupamento das línguas Arawák analisadas

\begin{tabular}{|l|l|}
\hline Línguas Arawák do Norte & Línguas Arawák do Sul \\
\hline Achaguá & Baure \\
\hline Baniwa de Içana/Kurripako & Mehináku \\
\hline Baré & Paresi \\
\hline Palikur & Terena \\
\hline Warekena & Wauja \\
\hline
\end{tabular}

Fonte: Adaptado de Aikhenvald (1999, p. 66-69)

Os materiais utilizados partem da compilação de estudos que tratam de aspectos referentes à morfossintaxe e que possibilitou a verificação dos padrões de gênero nessas línguas. Desse modo, para a língua Achaguá utilizamos o trabalho de Wilson e Levinsohn (1992) que aborda diferentes aspectos gramaticais da língua e um deles é a questão de gênero. A língua Achaguá é falada na Amazônia Colombiana e Venezuela e está em perigo de extinção. Para a língua Baniwa-Kurripako, utilizamos o trabalho de Aikhenvald (2007). A língua Baniwa-Kurripako é falada nos afluentes do Rio Negro, na bacia do Içana, nas cidades de São Gabriel da Cachoeira, Santa Izabel e Barcelos, no estado do Amazonas. Utilizamos o trabalho de Aikhenvald e Green (1998) para verificar o sistema de gênero em Palikur. Essa língua é falada no estado do Amapá, no município de Oiapoque, na região da bacia do rio Uaçá e também na fronteira entre Brasil e Guiana-Francesa. Para língua Warekena utilizamos a pesquisa de Aikhenvald (1998), essa língua é falada também no Alto Rio Negro e no afluente do Rio Xié.

A língua Baure é falada no noroeste da Bolívia, na parte da Amazônia boliviana, agrupada no grupo Sul-Arawák. O trabalho utilizado para analisar o sistema de gênero nessa língua foi a tese de doutorado de Danielsen (2007) que esboça algumas considerações sobre esse fenômeno. As línguas Mehináku e Wauja são faladas no Alto Rio Xingu, são inseridas juntamente com Paresi, no ramo Paresi-Xingu, fazendo parte do grupo das línguas do Sul-Arawák. Para a língua Mehináku, utilizamos o trabalho de Corbera Mori (2012) e Awetí (2014), já a tese de Postigo (2014) foi utilizada para verificar o sistema de gênero em Wauja. Para língua Paresi-Haliti utilizamos a tese de Brandão (2014) para analisar a questão de gênero nesta língua. A língua Paresi-Haliti é falada no estado do Mato Grosso. A língua Terena é falada no estado do Mato Grosso do Sul e os trabalhos utilizados foram de Butler e Ekdahl (1979) e Rosa (2010). 
Essas línguas, no geral, têm um sistema bastante rico de categorização nominal, como classificadores, termos de classe e gênero/classe nominal. A seção seguinte explica a questão de gênero/classe nominal e como esses termos são descritos na linguística.

\section{A questão de gênero/classe nominal}

Existe uma ambiguidade na definição ou divisão dos termos "gênero" e "classe nominal". Conforme Kilarski (2013), eles são tradicionalmente usados em referências para classificação de nomes em línguas Indo-Europeia e Bantu. A partir das línguas Bantu, o termo "classe nominal" é frequentemente usado para o sistema baseado no sexo (macho/fêmea). Para a autora, ambos termos têm sido usados em estudos comparativos e tipológicos para caracterizar as categorizações por concordância. O termo gênero é geralmente reservado para os sistemas relativamente pequenos baseados no sexo, do tipo Indo-Europeu, já a outra categorização envolve o uso de termos "classe" e "gênero" em descrições das línguas Bantu que se refere não apenas a marcas de singular e plural sobre os nomes e seus modificadores, mas também a seus pares.

De acordo com Corbett (2001), a característica definidora do gênero é a concordância, ou seja, uma língua tem um sistema de gênero apenas se o sintagma nominal nucleado por nomes de tipos diferentes controlar a concordância. De acordo com Aikhenvald (2000), o termo gênero foi usado pela primeira vez no século $V$ a.C pelo filósofo grego Protágoras, quando ele dividiu os substantivos do grego em três classes: "feminino", "masculino" e "inanimado" (hoje chamado de "neutro"). O latim do proto indo-europeu tinha um sistema similar; posteriormente, nomes neutros foram redistribuídos entre os outros dois gêneros, dando o moderno sistema masculino e feminino, como no português, francês e italiano.

Em muitas literaturas, o sistema de gênero insere as classes nominais (cf. CORBETT, 1991; AIKHENVALD, 2000a). Corbett (1991), por exemplo, afirma que uma língua pode ter duas ou mais classes nominais ou gêneros. Para o autor, a palavra gênero é usada não apenas para um grupo de nomes, mas também para toda uma categoria. Desse modo, podemos afirmar que uma língua particular pode ter três tipos de gêneros: masculino, feminino e neutro. Aikhenvald (2000a) afirma que as classes dos nomes e gênero são sistemas de concordância gramaticalizados que se correlacionam com algumas características semânticas do referente, por isso que as vezes são chamados de classe de concordância.

Contudo, diferentemente de Corbett (1991), Aikhenvald (2000a) e Kilarski (2013) que tratam os sistemas de gênero e classe nominal juntos, Grinevald (2000) discute os dois sistemas separadamente. A autora assume que a característica principal de um sistema de gênero é que o mesmo é um tipo de classificação nominal que nem sempre é evidente no próprio nome, mas pode ser codificado em outros elementos da sentença (artigos, pronomes) que variam de língua para língua. Grinevald explica que o sistema 
de gênero pode ter uma ordem decrescente de probabilidade, tal como, dentro de um sintagma nominal, adjetivo, demonstrativo, artigo, numerais, em construções de posse, dentro de uma forma pronominal independente, como pronomes pessoais, relativos ou em questões interrogativas. Os gêneros podem também estar presentes em orações predicativas como elementos que marcam a concordância dos argumentos do núcleo. Em outros lugares dentro da sentença, raramente eles ocorrem com advérbios, adposições ou complementizadores (cf. GRINEVALD, 2000).

O sistema de gênero/classe nominal é tratado como um dos principais sistemas de classificação nominal. Esse sistema é contrastivo com o sistema de classificadores, uma vez que esse último sistema não exige concordância. Assim sendo, o gênero/classe nominal é sempre refletido na forma de constituintes dentro e/ou fora do SN e também pode ser marcado no próprio substantivo. No que diz respeito aos princípios de atribuição, Kilarski (2013) afirma que os substantivos são atribuídos com base em propriedades semânticas como sexo ou animacidade, ou em combinação de propriedades semânticas e formais (morfológicas ou fonológicas). Em contraste, a escolha de um classificador não é baseada nas propriedades morfológicas ou fonológicas dos nomes; em vez disso, é determinado por propriedades do referente como animacidade, propriedades físicas, material, função e status social, e em alguns casos pode ser lexicalizado.

As línguas Arawák analisadas nesse trabalho apresentam atribuições de gênero/classe nominal por meio de propriedades formais e semânticas, uma característica importante sobre essas línguas é que elas apresentam uma marcação morfológica de gênero no verbo, ou em outras propriedades gramaticais (adjetivos, adposições, demonstrativos), realizando um fenômeno chamado de trans-referência. Nota-se também que algumas línguas não apresentam afixos de gêneros presos gramaticalmente, mas fazem uma referência a esse sistema por meio do léxico atribuindo o gênero semanticamente. A seção a seguir exemplifica a questão de gênero nas 10 línguas Arawák analisadas para esse trabalho.

\section{Exemplificando o gênero nas línguas Arawák analisadas}

O gênero é uma categoria relevante em muitas línguas do mundo, nas línguas Arawák é um aspecto presente. De acordo com Aikhenvald (1994), a proposta de que o gênero como categoria gramatical do nome baseada em uma oposição prototípica entre masculino e feminino forma um traço comum nessas línguas. Conforme Corbett (1991), nas línguas do mundo, classe nominal (classe de concordância) inclui o conceito de gênero. O gênero gramatical é uma categoria notável, difuso em algumas línguas, presentes em línguas Indo-europeias e Draviana ou ausente em outras como nas línguas da família Urálicas (CORBETT, 2001). 
Em 1994, Aikhenvald realizou um estudo bastante denso sobre questões de categorização nominal nas línguas Arawák, focando em duas categorias principais: gênero e classificadores. Aikhenvald (1994) afirma que as línguas amazônicas apresentam dois ou mais conjuntos de classes de concordância simultaneamente, sendo um baseado na oposição feminino/masculino e outro envolvendo oposições semânticas (tais como estrutura, tamanho e características físicas do objeto). Para esse trabalho, focaremos apenas na questão de categorização por meio de gênero, uma vez que esse estudo é bastante complexo e interessante não apenas nas línguas aqui estudadas, mas também em outras línguas, principalmente das regiões da Amazônia.

Antes de iniciarmos a análise de gênero/classe nominal dessas línguas é importante delimitar as atribuições de gênero proposto por Corbett (1991), já que este artigo utiliza o pressuposto teórico do autor e a sua definição na realização dos padrões tipológicos de gênero nas línguas analisadas. De acordo com Corbett (2001), a atribuição de gênero pode ser feita a partir da semântica ou por aspectos formais: fonológico e morfológico. Em seguida, exemplificaremos a atribuição semântica e formal do gênero nas línguas Arawák. Um aspecto importante de observar é que as cinco línguas apresentadas do grupo Sul-Arawák apresentam predominantemente a atribuição de gênero por questão semântica, embora em alguns casos não tenha distinção de gênero na terceira pessoa do singular.

\section{Atribuição predominantemente semântica}

Para Corbett (1991), uma intrigante questão que interessa a linguistas e não linguistas é a forma como os nomes são alocados para diferentes gêneros. Como vimos anteriormente, a concordância é um traço determinante para atribuição desse sistema. No entanto, o falante nativo da língua deve conhecer o gênero de um nome em ordem para produzir a concordância correta, sem utilizar aspectos formais, nesse caso, a atribuição de gênero não estaria relacionada a uma concordância de aspectos formais, mas sim a questões semânticas. A atribuição de gênero a partir da semântica denota nomes humanos masculinos, femininos que inclui também divindades, corpo celestes, crianças, animais, biologia etc. Nas línguas Arawák selecionadas, verificam-se atribuição semântica de gênero predominantemente (com alguns aspectos formais, mas não regular) em Baure, Mehináku, Paresi, Terena e Wauja

\section{Baure}

Iniciando a análise com a língua Baure, Danielsen (2007) afırma que gênero é uma característica inerente, principalmente biológica e não gramatical. Apenas alguns seres animados femininos são considerados como gramaticalmente femininos e todos os outros nomes são masculinos. Embora essa língua não apresente o domínio de atribuição gramatical de gênero, esse sistema faz referência ao gênero com pronomes pessoais 
possessivos e demonstrativos em alguns termos (parentescos e seres animados femininos). Esses pronomes e clíticos só são distinguidos na terceira pessoa do singular².

Os seres inanimados são sempre referidos para masculino não marcado, enquanto os animados podem ser não marcados para gênero (os animais nessas línguas não são marcados). Somente seres humanos e alguns animais de estimação em narrativas têm distinção de gênero realizada. Danielsen (2007) explica que o gênero não é formalmente aparente no nome, mas existem formas supletivas para humanos, homens, termos de parentesco e alguns animais. A autora explica que alguns desses nomes têm uma forma geral que se refere genericamente para ambos os gêneros e existem gêneros específicos aos nomes. Um nome geral é -iron "parente" e os nomes específicos -en "mãe" e -ia "pai". A autora explica que esses nomes em geral são também relacionados ao gênero masculino não marcado e geralmente interpretados como masculino, enquanto a forma feminina tem que ser marcada por um determinante feminino, nesse caso pelo demonstrativo feminino ti.

\begin{tabular}{|c|c|c|c|}
\hline To niron & (2) & ti niron & to nirononev \\
\hline To ni=iron & & Ti ni=iron & To ni=irono=nev \\
\hline Art 1sg=parente & & Dem.f 1sg=parente & art $1 s g=$ parente-pl \\
\hline "Meu pai" & & "Esta minha mãe" & "Meus pais" \\
\hline to nia & (5) & tinen & \\
\hline To ni=ia & & Ti ni=em & \\
\hline ART ISG=PAI & & $D E M . F$ ISG $=M \tilde{A} E$ & \\
\hline "Meu pai" & & "Está minha mãe" & \\
\hline
\end{tabular}

(DANIELSEN, 2007, p. 117-118)

Em Baure, há também outras divisões masculina e feminina para outros termos de parentescos como avós, irmãos e tios. Danielsen (2007, p. 118) afırma que quando os animais são distinguidos por gênero, eles são procedidos por um determinante ou alternativamente, o nome animal é marcado por um modificador nominal etan "mulher" ou hir "homem".

2 Os Dados de Danielsen mostram que na verdade esses morfemas são nomes que se gramaticalizaram em morfemas com o intuito de marcar o gênero. 


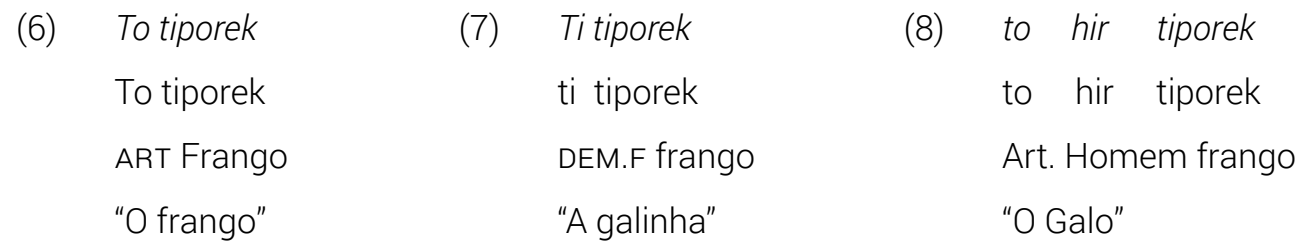

Desse modo, podemos compreender que a distinção de gênero em Baure não é uma característica gramatical, mas sim semântica, embora tenha alguns morfemas independentes marcando a distinção feminino/masculino. Essas distinções morfológicas são feitas através de nomes que designam parentescos, homem, mulher e são frequentemente referidas para seres animados. Embora não seja um traço presente, existe concordância em Baure com demonstrativos e afixos de terceira pessoa singular distinguindo os gêneros fixados nos verbos como nos exemplos (10) e (11).

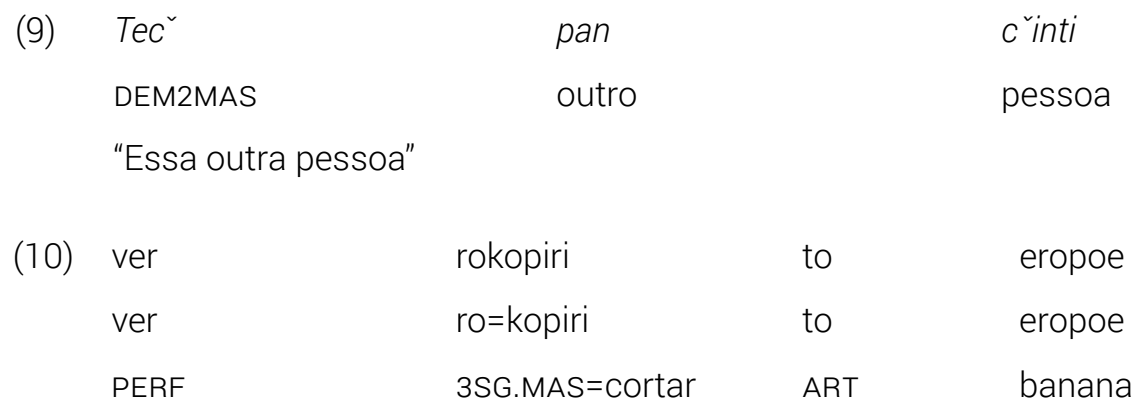

"A banana foi cortada no meio"

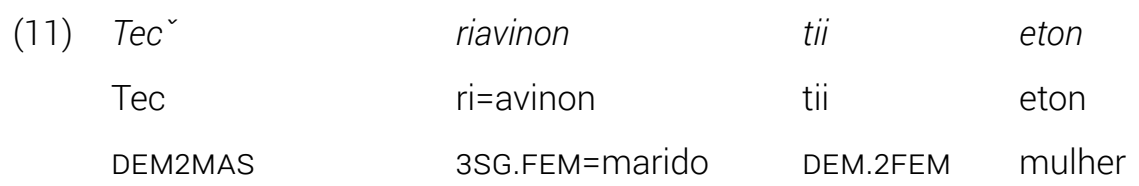

"Este é o marido da mulher"

(DANIELSEN, 2007, p. 310-312)

\section{Mehináku}

De acordo com Corbera Mori (2012, p.132), não há propriamente morfemas presos nos nomes que marcam a distinção de gênero. Conforme o autor, as diferenças se dão lexicalmente, atribuindo gênero por questões semânticas. Contudo, assim como correm Baure, alguns termos de parentescos recebem sufixos para indicar o masculino e o feminino. Nesse caso, os exemplos mostram que a forma masculina não é marcada ou em alguns poucos casos recebem o sufixo sii; já o feminino é marcado para distinguir o sexo com o sufixo -lu e suas variações ( -lulu- -şu). Os exemplos a seguir mostram distinção de gênero em termos de parentescos em Mehináku. 


$\begin{array}{lllll}\text { (12) } & \text { Nu-'tãı } & \text { 'meu filho' } & \text { N-itsu'pa-lu } & \text { 'minha filha' } \\ \text { (13) } & \text { Nu-tu'kaka } & \text { 'meu irmão' } & \text { Nu-taka'ka-lu } & \text { 'minha irmã' } \\ \text { (14) } & \text { Nu-matu'ki- și } & \text { 'meu sogro' } & \text { Nu-mati-şu } & \text { 'minha sogra' } \\ \text { (15) } & \text { Ka-tũ'pa- } s i & \text { 'viúvo' } & \text { ka-tũpa-'Iulu } & \text { 'viúva' }\end{array}$

(CORBERA MORI, 2012, p. 133)

Corbera Mori (2012) afırma que os sufıxos atachados nos nomes têm função derivacional e não flexional. Em alguns casos, a distinção de seres animados como os animais pode ser realizada a partir do léxico enisa "homem, macho" e tinesu "mulher, fêmea". Mas, assim como em Paresi (como veremos adiante), essa distinção é bastante rara na língua. Outra questão importante é a não distinção de gênero de terceira pessoa singular atachados nos verbos.

(16) $\varnothing$-ija waku
3SG-ir rio
"Ele/ela foi ao rio"

(AWETÍ, 2014, p. 164)

\section{Paresí-Haliti}

De acordo com Brandão (2014), em Paresi as categorias nominais são número, classificadores e tempo nominal. Gênero é um traço que tem se perdido, no entanto, alguns vestígios podem ser encontrados em nominalização e raramente em alguns léxicos que podem designar o sexo dos seres animados. Por exemplo, nessa língua os classificadores podem ocorrer com os nomes ohiro "mulher/fêmea" ou ena "homem/ macho" em compostos de animais, referindo-se ao gênero do referente. O classificador nesse caso é lexicalizado em alguns nomes. O exemplo a seguir exibe essa marcação de gênero por atribuição semântica em Paresí.

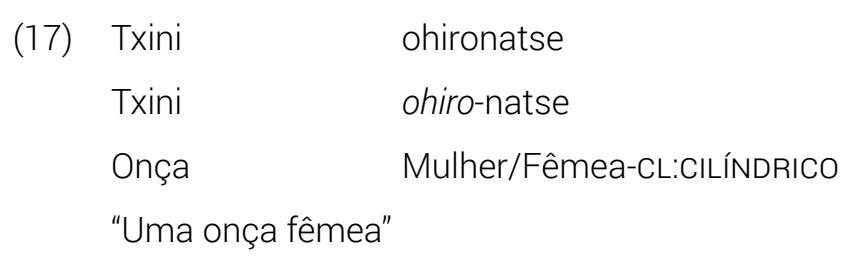

(BRANDÃO, 2014, p. 189)

Como o gênero é um sistema raro na língua, foi apenas possível encontrar um exemplo desse tipo em Paresi. Em alguns exemplos há vestígios morfológicos para marcar tal 
sistema, mas isto não é uma regularidade. Na questão da nominalização, há nomes que recebem a forma -hare para o masculino e -halo para o feminino, como podemos ver adiante.
(18) Aha? -hare
"seu irmão"
(19) Hareka?-hare
"hospedeiro"
(20) Aha-halo
"sua irmã"
(21) Hareka-halo
"hospedeira"

Segundo Brandão (2014), os nomes que recebem esses morfemas não são claramente nomes derivados. Desse modo, a autora afirma que esses morfemas nominalizadores são lexicalizados nessas formas com a única função de marcar o gênero de seus referentes. Os nominalizadores também são presentes em verbos intransitivos estativos, referindose às propriedades físicas (ex. wahahare "ser alto", tifalo "estar grávida"), apresentam também formas reduzidas fonologicamente -re ye (masculino) e -lo (para o feminino) em construções de predicados possessivos para mencionar o gênero do sujeito, mas a informação sobre o gênero pode também ser lexical (ohiro "mulher"/ena "homem"), se caso a marcação de gênero for lexical, a marcação de gênero por morfemas não é necessária. Não há distinção de gênero na terceira pessoa do singular, marcado como morfema zero $\{\varnothing\}$. Assim, como vimos em Mehináku e como vamos observar em Terena e Wauja. Desse modo, podemos observar que a língua está perdendo a distinção de gênero, apresentando esse aspecto só em alguns casos.

\section{Terena}

No que concerne à distinção de gênero da língua Terena, Butler e Ekdahl (1979, p. 20) afirmam que não há uma distinção formal de gênero. Rosa (2010) explica que há uma referência a seres humanos que distingue masculino e feminino nos nomes, mas essa marcação não é realizada morfologicamente. Na língua Terena há um item lexical específico para masculino hojens e outro item lexical especifico para feminino se:ns. Desse modo, podemos dizer que, em Terena, o gênero é expressado por uma atribuição semântica. Em Terena, a distinção de masculino e feminino é realizada por um item lexical, realizando uma atribuição semântica para distinguir um nome masculino do feminino, como podemos constatar nos exemplos abaixo:

\begin{tabular}{|c|c|c|}
\hline (22) se:no & kalivo:no & "Criança fêmea, menina" \\
\hline həjeno & kalivo:no & "Criança macho, menino" \\
\hline 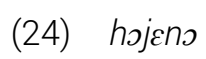 & si:ni & "Onça macho" \\
\hline se:no & si:ni & "Onça fêmea" \\
\hline
\end{tabular}

(ROSA, 2010, p. 81) 
Desse modo, podemos compreender que, em Terena, há atribuição de gênero por aspectos semânticos. Não verificamos nessa língua exemplos com marcação morfológica de trans-referência de gênero, ou seja, não há distinção gramatical de gênero marcado nos verbos ou em outros aspectos gramaticais.

\section{Wauja}

A língua Wauja não apresenta distinção de gênero por aspectos gramaticais e os dados de Postigo (2014) apontam para uma atribuição semântica dessa categoria. Postigo (2014) afirma que não há uma distinção de gênero para os nomes de seres inanimados. Já no que se refere aos seres animados, há uma distinção lexical de gênero masculino marcado com a palavra eneza "homem, macho" e tenezu "mulher, fêmea" para marcar o gênero feminino, como podemos observar nos exemplos abaixo.

\begin{tabular}{|c|c|c|c|}
\hline (26) & araukuma & eneza & "galo" \\
\hline (27) & araukuma & tenezu & "galinha" \\
\hline (28) & jãnumaka & eneza & "onça macho" \\
\hline (29) & jãnumaka & tenezu & "onça fêmea" \\
\hline
\end{tabular}

(POSTIGO, 2014, p. 143)

Assim como vimos em Paresi, há marcação de gênero em nomes derivados a partir do processo de nominalização. De acordo com Postigo (2014), os nomes formados a partir de derivação, na diferenciação entre "homem" e "mulher", ocorrem com o acréscimo do sufixo - hi para representar o "masculino" e -tsu para o feminino. Esses sufixos se afixam nos verbos para designar uma nominalização deverbal como podemos verificar nos exemplos a seguir.
(30) Wakulewekehi
(31) Wakuleweketsu
Wakule-weke-hi
Wakule-weke-tsu
Cozinhar-dono-MASC
Cozinhar-dono-FEM
"Cozinheiro (Lit. Dono da cozinha)"
"Cozinheira (Lit. Dono da cozinha)
(POSTIGO, 2014, p. 144)

Assim como ocorre em Mehináku, porém com nomes próprios, em Wauja observa-se a presença do morfema -lu para se referir ao gênero feminino, já o gênero masculino não é marcado morfologicamente. 


$$
\begin{aligned}
& \text { (32) } \text { Aruta } \rightarrow \text { Aruta-lu } \\
& \text { (33) Eju } \rightarrow \text { Eju-lu } \\
& \text { (34) Ulepe } \rightarrow \text { Ulepe-lu }
\end{aligned}
$$

(POSTIGO, 2014, p. 144)

Desse modo, podemos verificar que, em Wauja, a atribuição de gênero é predominantemente semântica, embora possa ter alguns vestígios formais. Na língua não encontramos exemplos de concordância de gênero em construções de transreferência; isso evidencia cada vez mais a atribuição de gênero por aspectos semânticos nessas línguas que compõem o grupo Sul-Arawák.

Corbett (1991) explica que atribuição semântica de gênero é um sistema em que o significado de um nome determina seu gênero e no qual, igualmente dado, o gênero de um nome pode inferir algo sobre seu significado. A subseção a seguir trata da atribuição de gênero formal nas línguas Arawák.

\section{Atribuição de gênero por aspectos formais}

Além da atribuição de gênero por aspectos semânticos, encontramos também nessas línguas atribuição de gênero por aspectos formais. Corbett (2001) explica que em muitas línguas a atribuição por regras semânticas não atribui muitos nomes a um gênero. Dessa forma, existem nomes cujos significados não permitem a atribuição de gênero por aspectos semânticos, o que leva a atribuir gênero por aspectos formais. O autor explica que essa regra é em torno de dois tipos: morfológico e fonológico. Em consonância com Corbett (2001), a distinção entre regras atributivas semânticas e formais são claras, no entanto, a distinção entre regras morfológicas e fonológicas não são. Para o autor, as regras fonológicas referem-se a uma forma simples de um nome (ex. nomes terminados em -a no português referem-se ao gênero feminino), já as regras morfológicas requerem o acesso à estrutura da palavra, tipicamente para flexionar informações das classes gramaticais.

Atribuição de gênero por aspectos gramaticais fornece ferramenta prática para iniciar análises de marcação explícitas de diferentes fenômenos gramaticais, como a transreferência. Cinco línguas pertencentes do grupo Norte-Arawák exibem a atribuição de gênero predominantemente por aspectos gramaticais. Lembrando que mesmo essas línguas apresentando uma atribuição formal evidente na categoria de gênero, algumas delas exibem também um núcleo semântico. Assim como destacou Corbett (1991, p. 308), "os sistemas formais de atribuição são, na verdade, sistemas semânticos mais formais". A subseção que segue apresenta a atribuição formal de gênero em Achaguá, Baré, Baniwa de Içana/Kurripako, Palikur e Warekena. 


\section{Achaguá}

Na língua Achaguá, foi possível identificar a atribuição de gênero por aspectos formais. Wilson (1992) explica que a concordância verbal tem duas formas, uma com sufixo e outra não. A forma com sufixo geralmente é usada para introduzir um novo tópico. Os sufixos de concordância com o sujeito são: -ezi (singular, menos terceira pessoa feminina), -eco (terceira pessoa singular, feminino) e -enai (plural). Há também prefixos que distinguem não-feminino li- do feminino zu-. Esses morfemas fazem uma construção de trans-referência, marcando o gênero gramatical nos verbos. Em tal situação, o verbo leva um prefixo nominal que concorda com o sujeito e um sufixo nominal que concorda com o complemento. Os exemplos a seguir exibem a atribuição de gênero por aspectos gramaticais em Achaguá.

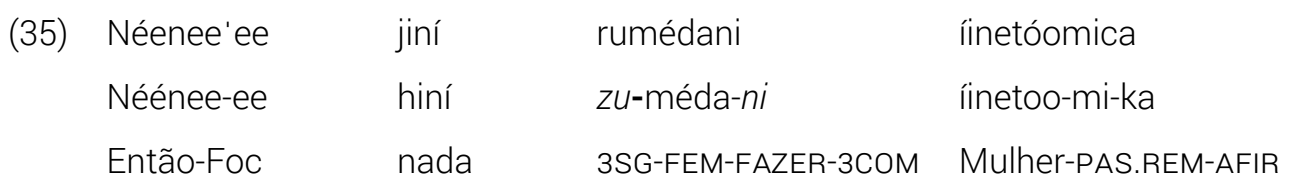

"Então a mulher não fez nada"

(36)

$\begin{array}{lll}\text { Samálita } & \text { wówairri } & \text { béerri } \\ \text { Sáama-li-ta } & \text { wówai-ezi } & \text { béézi } \\ \text { Criança-3SGM.-? } & \text { Querer-SG.N.FEM } & \text { Cazabe }\end{array}$

"O menino quer cazabe"

(37)

$\begin{array}{lll}\text { Ruya } & \text { wówaicho } & \text { éema } \\ \text { Zuyá } & \text { wóai-eco } & \text { éema } \\ \text { 3SG. FEM } & \text { QUERER-3SG.FEM } & \text { Cavalo }\end{array}$

"Ela quer um cavalo"

(WILSON, 1992, p. 6, 12 e 28)

Baré

De acordo com Aikhenvald (1995), a língua Baré tem uma oposição de dois gêneros em algumas nominalizações e resíduos de concordância de gênero na construção núcleomodificador. A língua apresenta concordância de gênero em construções de argumentopredicado e de núcleo-predicado. Os exemplos abaixo exibem a atribuição de gênero por aspectos morfológicos. 


\begin{tabular}{|c|c|c|}
\hline \multirow[t]{3}{*}{ (38) } & Herãri & I-KASA \\
\hline & Homem & 3S.G.N.F-CHEGAR \\
\hline & \multicolumn{2}{|c|}{ "Um homem chegou" } \\
\hline \multirow[t]{3}{*}{ (39) } & Hiñatfati & u-kasa \\
\hline & Mulher & 3SG.F-chegar \\
\hline & "Uma mı & ou" \\
\hline
\end{tabular}

(AIKHENVALD, 1995, p. 19)

Existe marcação de gênero também nas classes dos adjetivos como podemos verificar a seguir:
(40) Heñari
ma-kiate-ri
Homem
neg-medo-masc
"Um homem destemido"
(41) Hiñatfati ma-kiate-u
Mulher NEG-medo-FEM

"Uma mulher destemida"

(AIKHENVALD, 1995, p. 20)

\section{Baniwa lçana/Kurripako}

Baniwa de Içana/Kurripako combina um sistema de dois gêneros com classificadores usados em vários contextos. Baniwa/Kurripako tem dois gêneros (feminino e não feminino) distinguidos em demonstrativos singular, trans-referência de pessoas (prefixos e eclíticos), pronomes pessoais e com sufixos sobre os nomes, principalmente em termos de parentescos. Aikhenvald (2007) explica que formas femininas são usadas com referentes femininos e formas não femininas com o resto. Os exemplos a seguir exibem a atribuição de gênero morfológico em Baniwa de Içana/Kurripako.

\begin{tabular}{|c|c|c|c|}
\hline Hnete-pida & li-aku & hrie & itfida \\
\hline Então-REP & 3SG.MASC.A-FALA & PROX.DEM.MASC.SG & tartaruga \\
\hline
\end{tabular}




\begin{tabular}{|c|c|c|}
\hline (43) & Pédoro & ikaparo \\
\hline & Pedoro & i-kapa-ro \\
\hline & Pedro & CON-ver-3SG.FEM \\
\hline & "Pedro v & \\
\hline
\end{tabular}

(AIKHENVALD, 2007, p. 477; RAMIREZ, 2001, p. 105)

\section{Palikur}

A língua Palikur exibe atribuição de gênero por traços gramaticais, mas também semânticos. No que concerne à marcação de gênero por traços formais, ela é realizada por meio da trans-referência. De acordo com Aikhenvald e Green (1998), a concordância de gênero é realizada através do núcleo-modificador e predicado-modificador. Em Palikur, o gênero não é marcado sobre o próprio nome, a concordância de gênero é obrigatória. Três formas de gênero de concordância são encontradas nessa língua: masculino, feminino e neutro. Diferentemente das outras línguas Arawák apresentadas neste trabalho, a língua Palikur apresenta um gênero neutro que é recorrentemente usado quando se refere a um nome não animado. A distinção de gênero também pode ser realizada com pronomes demonstrativos, como podemos verificar nos exemplos abaixo.
(44) Ner
awayg
DEM=MASC
homem
"Este homem"
(45) No
Tino
$\mathrm{DEM}=\mathrm{FEM}$
Mulher
"Esta mulher"
(46) Ini
ahin
DEM-NEUTRO
Caminho
"Este caminho"

(AIKHENVALD; GREEN, 1998, p. 437)

Aikhenvald e Green (1998) explicam que a concordância também é presente em construções argumento-predicado. No exemplo em (47), observamos que o prefixo giatachado ao verbo wat faz referência ao sujeito (Karumaya). 
(47) $\mathrm{Ig}$

$\begin{array}{llll}\text { Karumaya } & \text { ig } & \text { ukokri } & \text { gi-wat-ni } \\ \text { Karumaya } & \text { 3M } & \text { Deus } & \text { 3SGMAS-enviar-Poss }\end{array}$

"Este Karumaya (homem) foi o mensageiro de Deus"

(AIKHENVALD; GREEN, 1998, p. 437)

De acordo com Aikhenvald e Green (1998), a trans-referência neutra é comumente usada em textos para marcar a concordância com um nome inanimado. Em (48), a concordância com o modificador demonstrativo é feminina, já a concordância com o possuidor é neutra.

\begin{tabular}{|c|c|c|c|c|}
\hline (48) & Eg & gi-waw-ni & nawene-wa & a-humwa-ni \\
\hline & DEM:F & 3SGM-chocalho-Poss & diferente:nf-EMPH & 3SGN-forma- \\
\hline & a-hum & & & \\
\hline & 3SG.NE & orma-Poss & & \\
\hline & “Este c & (feminino) dele tem u & forma diferente" & \\
\hline
\end{tabular}

(AIKHENVALD; GREEN, 1998, p. 438)

A concordância também pode ser observada em verbos estativos como modificadores em sintagmas nominais.

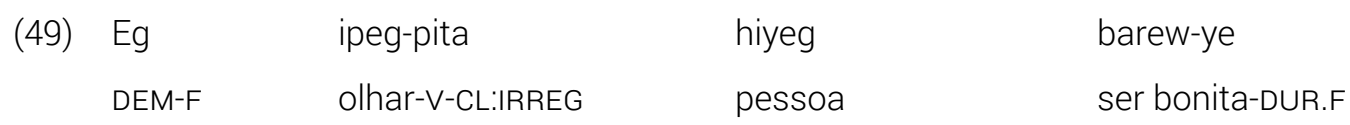

"Ela parecia uma pessoa bonita por todo o lado"

(AIKHENVALD; GREEN, 1998, p. 439)

Como dito anteriormente, a língua também apresenta atribuição de gênero por questões semânticas e essa atribuição também é bastante recorrente na língua. Desse modo, a atribuição de gênero de nomes humanos é governada pelo sexo (machos são masculinos e fêmeas são femininos). Aikhenvald e Green (1998) explicam que nomes que fazem referências aos corpos celestes (sol, lua, estrelas, planetas, trovões etc.) pertencem ao gênero masculino, pois para os Palikur, em suas narrativas tradicionais, eles eram homens. Já os pássaros, tartarugas e insetos são femininos por conta do tamanho (eles são pequenos). Se o sexo da pessoa é desconhecido, o gênero masculino é usado para um adulto e feminino para uma criança (AIKHENVALD; GREEN, 1998). Assim sendo, podemos compreender que a língua Palikur apresenta dois tipos de atribuição de gênero: formal e semântica. 


\section{Warekena}

A língua Warekena apresenta dois gêneros feminino e não feminino (masculino). Gênero é marcado em prefixos de trans-referência, enclíticos e pronomes independentes de terceira pessoa. Não existe distinção de gênero no plural. Para seres animados, masculino e feminino relaciona-se à distinção do sexo. Nomes com um referente inanimado são tratados como pertencentes ao gênero masculino. Desse modo, gênero masculino é considerado como não marcado nessa língua (AIKHENVALD, 1998). Os exemplos abaixo exibem a distinção de gênero por atribuição morfológica.
(50) ayuta
neyawa
yu-tapa-pa
DEM.DIST.FEM
mulher
3SG.F=ir-RED

"Esta mulher está vindo"

(AIKHENVALD, 1998, p. 298)

A concordância em gênero com adjetivo em atributivos SNs é marcado com -yawa "feminino" e não tem marcação para o masculino.
(51) Neyawa
weduana-li-yawa
Mulher
boa-ADJ-FEM

"Uma mulher boa"

(AIKHENVALD, 1998, p. 298)

Aikhenvald (1998) explica que a posição de gênero também é mantida em alguns nomes. O afixo derivacional -yawa ou -wa é usado para marcar feminino (ex. ete-ne "homem velho"; et-yawa "mulher velha", AIKHENVALD, 1998, p. 298). Desse modo, podemos verificar que a língua também tem atribuição de gênero por meio de traços semânticos. Contudo, os exemplos mostram que é mais recorrente a distinção por questões formais.

\section{Perfis tipológicos do gênero/classe nominal em línguas Arawák}

A seção anterior exemplificou a atribuição de gênero em dez línguas da família Arawák. A grande maioria apresenta uma atribuição semântica, embora as línguas do grupo Norte-Arawák tenham como predominância a atribuição desse sistema por questões gramaticais. Desse modo, podemos verificar que há uma distinção de atribuição de gênero semântico e formal nas línguas Arawák. É interessante notar que mesmo essas línguas fazendo parte de uma mesma família linguística, há padrões tipológicos diferentes no que 
diz respeito à questão de gênero gramatical e que esse sistema já está se perdendo em algumas línguas dessa família. 0 quadro 1 abaixo refere-se a essa divisão de atribuição do gênero nessas línguas.

Quadro 1. Atribuição de gênero por aspectos semânticos e morfológicos nas línguas Arawák

\begin{tabular}{|c|c|c|}
\hline Línguas & Semântico & Gramatical \\
\hline Achaguá & & $x$ \\
\hline Baré & $x$ & $x$ \\
\hline Baniwa-Kurripako & $\mathrm{x}$ & $\mathrm{x}$ \\
\hline Baure & $\mathrm{x}$ & \\
\hline Mehináku & $\mathrm{x}$ & $\mathrm{x}$ \\
\hline Paresí & $\mathrm{x}$ & \\
\hline Palikur & $\mathrm{x}$ & $\mathrm{x}$ \\
\hline Terena & & \\
\hline Warekena & $\mathrm{x}$ & \\
\hline Waujá & & \\
\hline
\end{tabular}

Fonte: Elaborada pela autora (2019)

Percebemos que a atribuição de gênero por aspectos semânticos é bastante recorrente nessas línguas. A marcação por atribuição formal é realizada através do processo de trans-referência. Observamos que as línguas que são do grupo Sul-Arawák, principalmente Mehináku, Paresi-Haliti, Terena e Wauja não apresentam distinção de gênero da terceira pessoa, diferente de Baure que tem. Uma hipótese que necessita ser mais aprofundada pode explicar essa perda seja por um processo de contato areal com línguas não geneticamente semelhantes ou processos diacrônicos. Observamos que, quando há distinção de gênero, ela ocorre especificamente na terceira pessoa do singular e os morfemas são atachados nos verbos ou em outras categorias gramaticais. Em algumas línguas, há pronomes demonstrativos que distinguem masculino e feminino. Em outras, a marcação é feita com morfema zero $\{\varnothing\}$.

\section{Considerações finais}

O presente trabalho mostrou de forma preliminar os diferentes tipos de distinguir gênero. Observamos que Corbett $(1991,2001)$ e Aikhenvald (2000) não distinguem gênero de classe nominal, inserindo-os em uma mesma categoria de classificação nominal. No entanto, Grinevald (2000) apresenta uma divisão, alegando que gênero está mais relacionado com questões de marcação morfológica de masculino e feminino enquanto classes nominais estão relacionadas às questões semânticas de um nome (ex. animado/ 
não animado; macho/fêmea). A análise realizada neste estudo é através da proposta de Corbett (1991) que sugere classe de nomes e gênero em uma mesma categoria.

De acordo com Aikhenvald (2000), o sistema de gênero é geralmente composto por morfemas portmanteau combinando informações sobre classe nominal com número, pessoa, caso, etc. Grinevald assume que gênero é atribuído para todos os nomes de uma determinada língua e é obrigatoriamente marcado. Esse sistema é limitado na classificação nominal em termos de número em sua classe.

De acordo com Aikhenvald (1994), a proposta de que o gênero como categoria gramatical do nome baseada em uma oposição prototípica entre masculino e feminino forma um traço comum nas línguas Arawák. O estudo de categorização nominal torna-se fundamental para um estudo tipológico. A pesquisa contribui para determinar a questão de gênero como uma categorização nominal, assim como os classificadores, termos de classes, nomes classificatórios e posse. Dessa forma, o objetivo deste trabalho é iniciar uma revisão dos estudos do sistema de classificação nominal em línguas Arawák, focando na questão de gênero.

\section{REFERÊNCIAS}

AIKHENVALD, A. Y. Language of the Amazon: a bird's - eye view. In: AIKHENVALD, A. Y. The languages of the Amazon. Oxford/New York: Oxford University Press, 2012. p. 1-67. DOI: https://doi.org/10.1093/acprof:oso/9780199593569.003.0001.

AIKHENVALD, A. Y. Classifiers in Multiple Environments: Baniwa of Içana/Kurripako - A North Arawak Perspective. International Journal of American Linguistics, n. 4, p. 474-500, October, 2007.

AIKHENVALD, A. Y. Classifiers: a typology of noun categorization devices. Oxford: Oxford linguistic, 2000.

AIKHENVALD, A. Y. The Arawak language Family. In: DIXON, R. M.; AIKHENVALD, A. Y. The Amazonia languages. Cambridge: Cambridge University Press, 1999. p. 65-106.

AIKHENVALD, A. Y. Warekena. In: DERBYSHIRE, D. C.; PULLUM, G. K. (ed.). Handobook of Amazonian Languages. v. IV. Berlin e Nova York: Monton de Gruyter, 1998. p. 225-439.

AIKHENVALD, A. Y. Baré. Language of the world's materials. München-Newcastle: Lincom Europa, 1995. 
AIKHENVALD, A. Y. Classe Nominal e gênero nas línguas Aruák. Boletim do Museu Paraense Emílio Goeldi, Belém, v. 10, p. 137-258, 1994.

AIKHENVALD, A. Y.; GREEN, D. Palikur and typology of classifiers. Anthropological linguistics, v. 40, n. 3, p. 429-480, 1998.

AWETÍ, M. M. Uma descrição preliminar das classes de palavras da Língua Mehináku, com foco especial na classe dos nomes. 2014. Dissertação (Mestrado em Linguística) Instituto de Letras, Universidade de Brasília, Brasília, 2014.

BUTLER, N. E.; EKDAHL, E. M. Aprenda Terena. v. 1. Brasília: SIL, 1979.

BRINTON, D. G. The American race: a linguistic classification and ethnographic description of the native tribes of North and South America. Studies in South American native languages. Philadelphia: MacCalla \& Company, 1891.

BRANDÃO, A. P. A Reference Grammar of Paresi-Haliti (Aruák). 2014. Tese (Doctor of Philosofy) - The University of Texas at Austin, Texas, 2014.

CORBETT, G. G. Gender Grammatical. International Encyclopedia of the Social Sciences, p. 6335-6340, 2001.

CORBETT, G. G. Gender. Cambridge: Cambridge University Press, 1991.

CORBERA MORI, A. Estruturas Lexicais na Língua Mehináku. In: FARGETTI, C. M. Abordagens sobre o léxico em línguas indígenas. Campinas: Curt Nimuendajú, 2012. p. 127-143.

DANIELSEN, S. Baure: an Arawak language of Bolivia. In: DANIELSEN, S. Indigenous Languages of Latim America. Leiden: CNWS Publications: Universiteit Leiden, The Netherlands, 2007.

GILIJ, F. S. Saggio di storia americana, o sia, Storia naturale, civile e sacra dei regni, e delle provincie spagnuole di Terra Ferma nell'America Meridionale descritto dall'abate F. S. Gilij. Rome: 1783.

GRINEVALD, C. A morphosyntactic typology of classifiers. In: SENFT, G. Systems of Nominal Classification. Cambridge: University Press, 2000. p. 50-92. 
KILARSKI, M. Nominal Classification. Amsterdam: Ed. John Benjamins Publishing Company, 2013.

LUCY, J. A. Systems of Nominal Classification: A concluding discussion. In: SENFT, G. Systems of Nominal Classification. Cambridge, UK: Cambridge University Press, 2000. p. 326-341.

PAYNE, D. L. A classification of Maipuran (Arawakan) languages based on shared lexical retentions. In: DERBYSHIRE, D. C.; PULLUM, G. K. Handbook of Amazonian languages. v. 3. Berlin/New York: Mouton De Gruyter, 1991. p. 355-499.

POSTIGO, A. V. Língua Wauja (Arawak): uma descrição fonológica e morfossintática. 2014. Tese (Doutorado em Linguística) - Faculdade de Ciências e Letras, Universidade Estadual Paulista Júlio de Mesquita Filho, Araraquara, 2014.

RAMIREZ, H. Uma gramática do Baniwa de Içana, 2001a (ms).

ROSA, A. M. Aspectos Morfológicos da língua Terena (Aruák). 2010. Dissertação (Mestrado em Letras) - Universidade Federal do Mato Grosso do Sul, Três Lagoas, 2010.

VON DEN STEINEN, K. Unter den Naturvölkern Zentral-Brasiliens: Reiseschilderung und Ergebnisse der zweiten Schingú-Expedition (1887-1888). Berlin: Hoefer \& Vohsen, 1894.

WILSON, P. J; LEVINSON, S. H. Una descripcion preliminar de la gramatica Del Achagua. Bogotá: Instituto Linguistico de Verano (SIL), 1992. 